\title{
The Role of Empathy in Therapy and the Physician- Patient Relationship
}

\author{
Bhautesh Dinesh Jani David N. Blane Stewart W. Mercer \\ General Practice and Primary Care, Institute of Health and Well Being, University of Glasgow, UK
}

\author{
Keywords \\ Empathy · Clinical empathy · Physician-patient \\ relationship · Therapy · Health outcomes
}

\section{Summary}

This paper seeks to give an overview of the role of clinical empathy in therapy and in the physician-patient relationship. Researchers have offered definitions of empathy in the clinical context, and a number of validated measures exist. There is evidence from the health-related research literature to support the positive association of clinical empathy with improved therapeutic outcomes in a wide range of clinical settings. Clinical empathy is also understood to be a crucial component of the physician-patient therapeutic relationship. Barriers to the development and expression of empathy in the clinical context are explored, and ways of enhancing empathy discussed.

\section{Introduction}

The word 'empathy' originates from the German word 'Einfühlung' ('in + feeling') which in turn was translated from the Greek word 'empatheia' ('physical affection, passion') [1].

Empathy is a concept which can have somewhat different meanings depending on the context. Merriam-Webster's dictionary defines empathy as 'the action of understanding, being aware of, being sensitive to, and vicariously experiencing the feelings, thoughts, and experience of another of either the past or present without having the feelings, thoughts, and experience fully communicated in an objectively explicit manner' [2].

\section{KARGER \\ Fax +497614520714 \\ Information@Karger.de}

www.karger.com (c) 2012 S. Karger GmbH, Freiburg

$1661-4119 / 12 / 0195-0252 \$ 38.00 / 0$

Accessible online at:

www.karger.com/fok

\author{
Schlüsselwörter \\ Empathie - Klinische Empathie · Arzt-Patient-Verhältnis . \\ Therapie $\cdot$ Gesundheitszustand
}

\section{Zusammenfassung}

Dieser Artikel soll eine Übersicht zur Rolle der klinischen Empathie in der Therapie und dem Arzt-Patient-Verhältnis darstellen. Wissenschaftler haben Definitionen von Empathie im klinischen Kontext angeboten, und einige bestätigte Erkenntnisse sind vorhanden. Belege aus der gesundheitsbezogenen Forschungsliteratur stützen die positive Verbindung klinischer Empathie mit verbesserten therapeutischen Ergebnissen in einem breiten Spektrum klinischer Settings. Klinische Empathie wird auch als wichtige Komponente des therapeutischen Verhältnisses zwischen Arzt und Patient verstanden. Beschränkungen in der Entwicklung und dem Ausdruck von Empathie im klinischen Kontext werden erforscht und Möglichkeiten der Förderung von Empathie diskutiert.
The concept of clinical empathy has evolved over the last decade. A systematic review by Di Blasi et al. [3] suggested that physicians who display a warm, friendly, and reassuring manner with their patients are more effective. The Society of General Internal Medicine (SGIM) defined clinical empathy as 'the act of correctly acknowledging the emotional state of another without experiencing that state oneself' [4]. In contrast, Halpern [5] argued that physicians' emotional attunement greatly serves the cognitive goal of understanding patients' emotions.

Bohart and Greenberg [6] reviewed the many definitions of empathy within psychotherapy and concluded that they have in common, 'trying to sense, perceive, share or conceptu- 
alise how another person is experiencing the world'. Morse [7] conducted an extensive literature review on empathy, and summarised the 4 key components of empathy. They were: 1 . Emotive component: the ability to subjectively experience and share in another's psychological state or intrinsic feelings. 2. Moral component: an internal altruistic force that motivates the practice of empathy. 3. Cognitive component: the helper's intellectual ability to identify and understand another person's feelings and perspective from an objective stance. 4 . Behavioural component: communicative response to convey understanding of another's perspective.

Similarly, Barrett-Lennard [8] developed a multi-dimensional model of clinical empathy, referred to as the "empathy cycle', which consists of 3 phases. Phase 1 is the inner process of empathetic listening to another who is personally expressive in some way, reasoning, and understanding; phase 2 is the attempt to convey empathetic understanding of the other person's experience; and phase 3 is the client's actual reception or awareness of this communication.

As to an exact definition of clinical empathy, it is unlikely that 1 definition is adequate to cover all components and all clinical encounters and situations, but there are certain elements that are common to most definitions. For example, Coulehan et al. [9] proposed a simple definition for clinical empathy: 'the ability to understand the patient's situation, perspective and feelings, and to communicate that understanding to the patient'. Mercer and Reynolds [10] argued that clinical empathy is ineffective without a behavioural or action component, i.e., without demonstrating unequivocally that physicians do indeed grasp what the patient is experiencing, and are able to act accurately on the basis of this understanding. This, in turn, requires a feedback loop checking back with the patients that they have understood correctly.

\section{Is Clinical Empathy Associated with Improved Therapeutic Outcomes?}

The role of clinical empathy in improving therapeutic outcomes has been studied extensively by researchers in a range of clinical settings, but empathy research originated in the field of psychology, and it has been of particular interest to psychotherapy researchers. Orlinsky, Gawe and Parks' [11] review of 115 studies of therapeutic empathy and outcome in psychotherapy reported that in over half the studies, therapeutic empathy was significantly correlated with therapeutic outcome. They also found that when therapeutic empathy was assessed by patients, empathy was positively correlated with recovery in 34 of 47 studies. A more recent meta-analysis of 59 studies by Elliott et al. [12] showed that empathy was moderately associated with improved therapeutic outcomes in psychotherapy, irrespective of the type of psychotherapy. Burns and Nolen-Hoeksema [13] demonstrated that thera- peutic empathy has a moderate-to-large causal effect on recovery from depression in a group of 185 patients (aged 18-75 years) treated with cognitive-behavioural therapy (CBT). The authors simultaneously estimated the reciprocal effects of depression severity on therapeutic empathy and found that this effect was quite small.

Compared to mental health settings, the evidence for empathy improving clinical outcomes in other clinical contexts is more limited, though there is good evidence of positive associations between clinician empathy and patient satisfaction and enablement. In a study of 710 cancer patients in Germany, for example, clinical empathy was positively associated with improvement in patient-reported outcomes measured by major depression inventory (MDI) and European Organisation for Research and Treatment of Cancer (EORTC) quality of life (QoL) questionnaire QLQ-C30 [14]. Clinical empathy also led to improvement in patient enablement, and in turn improvement in patient-reported outcomes in a study of general practice (GP) consultations with 323 patients living in high deprivation areas of Scotland [15]. In a study of 1,015 out-patients attending 25 consultants across 10 different specialties, clinical empathy was positively related with increase in patient satisfaction and whether the patients would recommend the physician [16]. In an interesting randomised controlled trial of 719 clinical encounters with patients with common cold in the USA, an increase in patient-perceived empathy was associated with reduction in severity and duration of symptoms [17]. Recently, Hojat et al. [18] showed that physicians' empathy was associated with positive clinical outcomes for diabetic patients, as measured by improvement in HbA1C results, in a study of 891 diabetic patients.

The association between improved therapeutic outcomes and clinical empathy has also been demonstrated in complementary medicine settings, though the study numbers have been small. Price et al. [19] in a study of 52 patients showed that increase in empathy in acupuncture consultations predicted better health outcomes for patients at 8 weeks, as measured by Measure Yourself Medical Outcome Profile (MYMOP). Bikker et al. [20] showed that empathy in homeopathy consultations was positively associated with improvement in patient complaint and well-being at 3 months, in a study of 117 patients.

\section{How Does Clinical Empathy Improve Outcomes?}

Neumann et al. [21] proposed a model to explain the possible mechanism by which clinical empathy in the physician-patient relationship might improve therapeutic outcomes (fig. 1). Empathic communication in a clinical encounter can achieve various positive effects. To begin with, patients are likely to tell more about their symptoms and psychosocial concerns to an empathic physician $[9,22,23]$. This enhanced medical and psychosocial information sharing leads to a more accurate di- 
Fig. 1. Effect model of empathic communication in the clinical encounter - proposed by Neumann et al. [14].

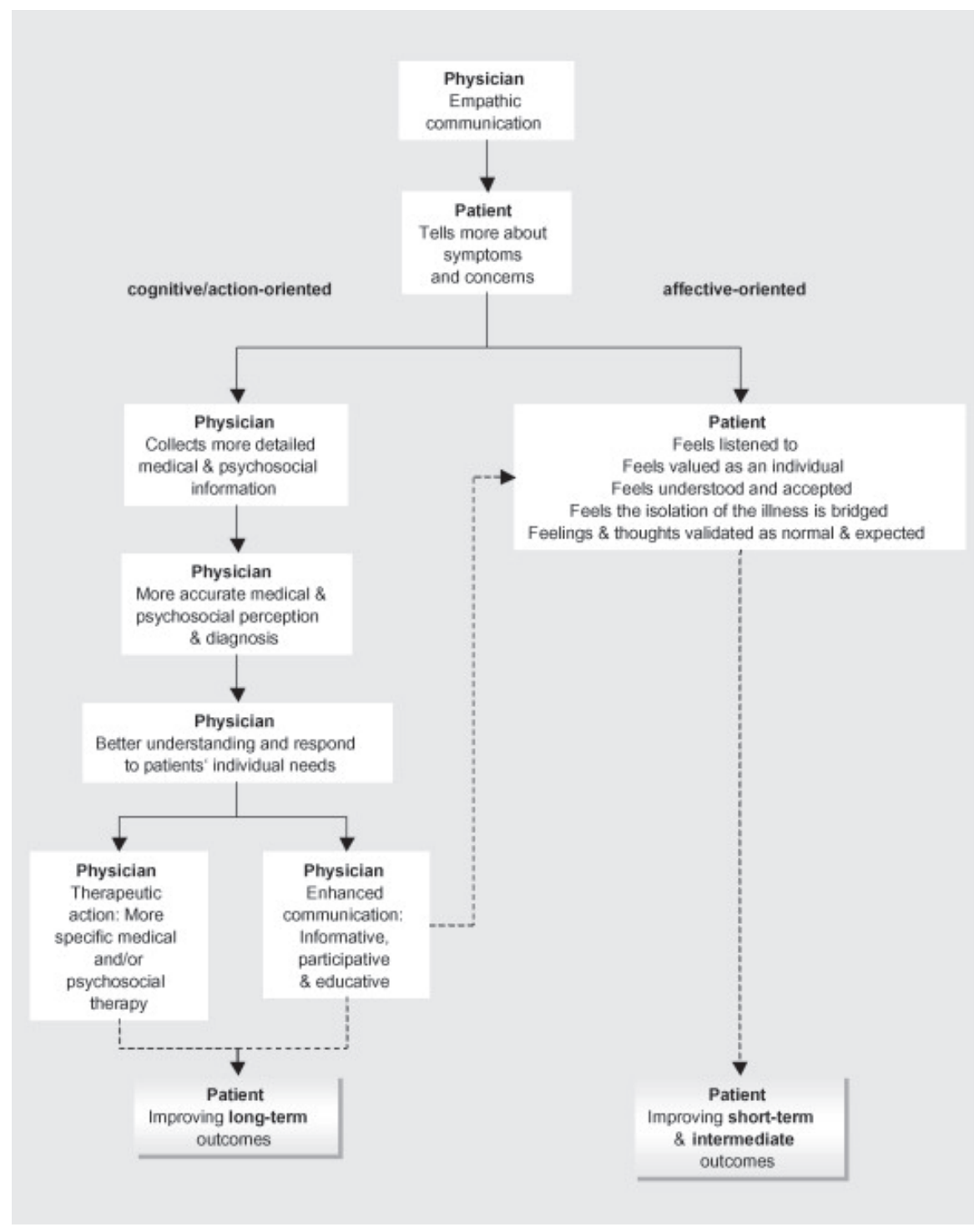

agnosis [24, 25]. Additionally, the empathic physician is able to identify with the patient and has a better understanding of individual patients' needs [26].

Consequently, empathic physicians can reciprocate by means of specific medical/psychosocial therapies and provide appropriate illness-related information, allowing patient participation while doing so $[10,19,27,28]$. This, in turn, leads to improvements in patient satisfaction, patient enablement and compliance with proposed therapies [19, 28, 29]. These positive effects of clinical empathy on an efficient patient-physician relationship are thought to explain its association with improved outcomes in therapy.

Importantly, empathic consultation has advantages for the physician as well. Roter et al. [30] found that physicians with an engaged, psychosocially oriented communication style experience burnout less frequently than others.

\section{Measurement of Clinical Empathy}

Hemmerdinger et al. [31] did a systematic review of tests of empathy in medicine. They identified 50 relevant papers describing 59 different instruments for measuring empathy in the medical consultation. However, they found only 8 instruments to have an evidence base supporting their reliability (inter-rater or test-retest) and valid internal consistency. Of these, 6 were self-rated measures, which were labelled by the authors as first person measures. They were: Medical Condition Regard Scale (MCRS) [32], Jefferson Scale of Physician Empathy (JSPE) [33], Empathy Test (ET) [34], Empathy Construct Rating Scale (ECRS) [35], Davis' Interpersonal Reactivity Index (DIRI) [36] and Balanced Emotional Empathy Scale (BEES) [37]. According to the systematic review, all of the 6 tests had evidence supporting their test-retest and inter-rater reliability but none of these first person measures were correlated with empathy or patient care, as judged by 
patients. However, in a study published last year, Hojat et al. [18] have shown that empathy measured by JSPE is associated with better clinical outcomes (improvement in HbA1C) in diabetic patients.

The review concluded that only 1 measure, the Consultational and Relational Empathy (CARE) measure, had suitable validity and reliability for measuring physician empathy from the patients' perspective [38]. The CARE measure not only has high internal consistency, but also demonstrates other important aspects - reliability and validity [39].

The final, 8th instrument was the Four Habits Coding Scheme (FHCS), an observer-rated measure, which showed validated internal consistency [40]. The FHCS was correlated with patient evaluations of care, but correlation was not statistically significant.

In the field of psychotherapy, the Barrett-Lennard Relationship Inventory (BLRI) [41] and the 10-item Empathy Scale (ES) devised by Persons and Burns [42] are widely used patient-rated measures of empathy measurement. The BLRI is based on operational definition of Rogers' hypothesis that client's perceptions of therapists' facilitative conditions (positive regard, empathy and congruence) predict therapeutic outcome [43]. One of the earliest empathy measurement scales was developed by Truax and Carkhuff in 1967 [44], which was observer-rated. Typically, trained raters listened to 2- to 5-min samples from psychotherapy session tapes. More recently, observer-rated empathy measures have been developed which measure multiple component elements of empathy $[45,46]$. Finally, BLRI has a self-rating component which measures therapist's rating of empathy.

There is considerable evidence to suggest that patientrated empathy in clinical encounters is more reliably associated with better therapeutic outcomes than self-rated empathy, both in medicine and psychotherapy $[11,12,21]$.

\section{Barriers and Facilitators of Empathic Consultation}

Researchers have studied various factors which help or hinder empathic consultation in medicine, medical education and psychotherapy. These can be broadly divided into physician factors, situational factors and patient factors.

Several studies have demonstrated a decline in empathy over the course of medical training, both during medical school and during early hospital training. A systematic review of such studies concluded that physician distress (e.g., burnout, stress, reduced QoL) was a significant factor in self-assessed empathy decline [47]. Although this may seem to contradict the work that suggests empathy is protective of burnout [30] it should be noted that these studies employed different research designs (cross-sectional and longitudinal) and studied physicians at different stages of their careers.

Non-verbal communication or body language could be equally important as verbal communication. Various studies of client's experience of psychotherapist's empathy have shown that non-verbal skills such as therapist's posture and maintaining eye contact could improve perceived empathy, along with verbal skills such as using emotion words, giving advice and not interrupting [48-50]. Another potential individual physician factor affecting empathy is gender, with 1 paper reporting that female medical practitioners are more empathic than male, though this is variable and likely to be influenced by other factors [51].

Situational factors like time are important, with lack of time being a barrier for an empathic consultation. For instance, there is evidence that more time leads towards higher patient-perceived empathy in UK GP consultations [52]. The degree of familiarity between psychotherapist and client influences the level of empathy, underlining the importance of continuity of care [49]. Other contextual factors, like institutional culture and workload, may have a considerable impact on an individual's ability to behave empathically. There is some evidence, for instance, that doctors working in more person-oriented medical specialities (like GP) have higher levels of empathy than those working in, e.g., surgical specialities [53].

Finally, patient factors are likely to be an important contributor. For example, studies have found that levels of empathy in psychotherapy were higher with clients who had less clinical dysfunction and who were brighter [54]. As BarrettLennard [8] pointed out, the patients' sharing of their experience is an essential link in the cycle of empathy. This is likely to be influenced by patients' individual personality and other factors such as self-awareness and ability to communicate clearly, which may in turn be influenced by socioeconomic factors like level of education.

\section{Can Clinical Empathy Be Enhanced Through Training?}

It has been argued that if empathy can decline during medical training then it should also be possible to enhance clinical empathy by targeted educational programmes [53]. Empathy has been considered a core element of professionalism in medicine, incorporated into many undergraduate medical curricula [55]. Different approaches to enhance empathy in healthcare students have been explored. These have ranged from experiential learning with 'patient simulations' (where students are placed in scenarios that their patients might face) [56] and 'patient navigators' (where students accompany patients over the course of a hospital admission) [57] to a more traditional focus on communication skills, both verbal and non-verbal [58].

Of course, programmes to increase empathy do not end at university. There is a growing number of post-graduate courses in areas such as mindfulness, with some evidence of their positive effects. For example, Krasner et al. [59] have demonstrated that mindfulness training can significantly improve physician empathy, mood disturbance, and burnout. In 
a similar vein, the work of Gilbert and colleagues [60] in compassion-focussed therapy, which has clear overlaps with empathy, has attracted worldwide attention. Again, the mechanism of action regarding how mindfulness training improves empathy is not clear, and further research is required on this.

Nevertheless, the concept of clinical empathy does not have unanimous support. Some commentators dispute the very idea of being able to achieve empathy in a therapeutic consultation. For example, McNaughton [61] contends that 'true empathy derives from an experience of intersubjectivity and this cannot be achieved in the doctor-patient relationship'. She does, however, believe that physicians can and should sympathise with their patients, and respond accordingly, so it could perhaps be argued that the dispute is more around semantics and definitions than a wholesale rejection of the concept itself.

\section{Conclusion}

Clinical empathy is a complex, multi-dimensional concept. However, it is widely accepted that it involves cognitive and affective elements and both verbal and non-verbal communication. Clinical empathy may improve health outcomes by enhancing physician-patient communication and making the consultation more effective. It is highly valued by patients, improving both self-reported satisfaction and enablement. As such, it also has a role in measuring physician performance and as an assessment tool in medical education, with patientrated measurement tools for clinical empathy being more predictive of outcomes than self-rated measurement tools. Importantly, there is evidence to suggest that empathic therapeutic encounters are associated with better outcomes, although there is more evidence for this in mental health problems than physical health problems. The larger evidence base supporting better outcomes for mental health problems is reflective of the fact that the role of empathy has been investigated more often for mental health problems. There is, however, emerging evidence to suggest that empathy may have a role to play in improving physical health outcomes, especially in chronic disease management.

Several factors related to the physician, the patient and the environmental context are likely to influence clinical empathy - some positively (like increased consultation time and doctor-patient familiarity); others negatively (like stress and workload). Further research in this area should focus on contextual factors in and around the clinical encounter which contributes towards an empathic consultation, and on ways of augmenting these factors in education and practice.

\section{Disclosure Statement}

The authors declare no conflict of interest.

\section{References}

1 Online Etymology Dictionary. www.etymonline. com/index.php? search $=$ empathy\&searchmode $=n$ one.

2 Merriam-Webster's Dictionary. www.dictionary. reference.com/browse/empathy.

3 Di Blasi Z, Harkness E, Ernst E, Georgiou A, Kleijnen J: Influence of context effects on health outcomes: a systematic review. Lancet 2001;357: $757-762$.

4 Markakis K, Frankel R, Beckman H, Suchman A: Teaching empathy: it can be done. Working paper presented at the Annual Meeting of the Society of General Internal Medicine. San Francisco, CA, 1999.

5 Halpern J: What is clinical empathy? J Gen Intern Med 2003;18:670-674.

6 Bohart AC, Greenberg LS: Empathy: where are we and where do we go from here?; in Bohart AC, Greenberg LS (eds): Empathy Reconsidered: New Directions in Psychotherapy. Washington, DC, American Psychological Association, 1997, pp 419450.

7 Morse JM, Anderson G, Bottorff JL, Yonge O, O'Brien B, Solberg SM, McIlveen KH: Exploring empathy: a conceptual fit for nursing practice? Image J Nurs Sch 1992;24:273-280.

8 Barrett-Lennard GT: The empathy cycle: refinement of a nuclear concept. J Couns Psychol 1981; 28:91-100.
9 Coulehan JL, Platt FW, Egener B, Frankel R, Lin CT, Lown B, Salazar WH: 'Let me see if $\mathrm{i}$ have this right...': words that help build empathy. Ann Intern Med 2001;135:221-227.

10 Mercer SW, Reynolds WJ: Empathy and quality of care. Br J Gen Pract 2002;52(suppl):S9-12.

11 Orlinsky D, Grawe K, Parks BK: Process and outcome in psychotherapy; in Lambert MJ, Bergin AE, Garfield SL (eds): Handbook of Psychotherapy and Behavior Change, ed 4. New York, NY, Wiley, 1994.

12 Elliott R, Bohart AC, Watson JC, Greenberg LS: Empathy. Psychotherapy 2011;48:43-49.

13 Burns DD, Nolen-Hoeksema S: Therapeutic empathy and recovery from depression in cognitivebehavioral therapy: a structural equation model. J Consult Clin Psychol 1992;60:441-449.

14 Neumann M, Wirtz M, Bollschweiler E, Mercer SW, Warm M, Wolf J, Pfaff H: Determinants and patient-reported long-term outcomes of physician empathy in oncology: a structural equation modelling approach. Patient Educ Couns 2007;69:63-75.

15 Mercer SW, Neumann M, Wirtz M, Fitzpatrick B, Vojt G: General practitioner empathy, patient enablement, and patient-reported outcomes in primary care in an area of high socio-economic deprivation in Scotland - a pilot prospective study using structural equation modeling. Patient Educ Couns 2008; 73:240-245.
16 Mercer SW, Murphy DJ: Validity and reliability of the CARE measure in secondary care. Clin Gov Int J 2008;13:261-283.

17 Rakel D, Barrett B, Zhang Z, Hoeft T, Chewning B, Marchand L, Scheder J: Perception of empathy in the therapeutic encounter: effects on the common cold. Patient Educ Couns 2011;85:390-397.

18 Hojat M, Louis DZ, Markham FW, Wender R, Rabinowitz C, Gonnella JS: Physicians' empathy and clinical outcomes for diabetic patients. Acad Med 2011;86:359-64.

19 Price S, Mercer SW, MacPherson H: Practitioner empathy, patient enablement and health outcomes: a prospective study of acupuncture patients. $\mathrm{Pa}$ tient Educ Couns 2006;63:239-245.

20 Bikker AP, Mercer SW, Reilly D: A pilot prospective study on the consultation and relational empathy, patient enablement, and health changes over 12 months in patients going to the Glasgow Homoeopathic Hospital. J Altern Complement Med 2005;11:591-600.

21 Neumann M, Bensing J, Mercer S, Ernstmann N, Ommen O, Pfaff H: Analyzing the 'nature' and 'specific effectiveness' of clinical empathy: a theoretical overview and contribution towards a theorybased research agenda. Patient Educ Couns 2009;74:339-346.

22 Squier RW: A model of empathic understanding and adherence to treatment regimens in practitioner-patient relationships. Soc Sci Med 1990;30: 325-339. 
23 Maguire P, Faulkner A, Booth K, Elliott C, Hillier V: Helping cancer patients disclose their concerns. Eur J Cancer 1996;32A:78-81.

24 Beckman HB, Frankel RM: The effect of physician behavior on the collection of data. Ann Intern Med 1984;101:692-696.

25 Graugaard PK, Holgersen K, Finset A: Communicating with alexithymic and non-alexithymic patients: an experimental study of the effect of psychosocial communication and empathy on patient satisfaction. Psychother Psychosom 2004;73:92-100.

26 Matthews DA, Suchman AL, Branch WT Jr: Making 'connexions': enhancing the therapeutic potential of patient-clinician relationships. Ann Intern Med 1993;118:973-977.

27 Irving P, Dickson D: Empathy: towards a conceptual framework for health professionals. Int J Health Care Qual Assur Inc Leadersh Health Serv 2004;17:212-220.

28 Kim SS, Kaplowitz S, Johnston MV: The effects of physician empathy on patient satisfaction and compliance. Eval Health Prof 2004;27:237-251.

29 Bertakis KD, Roter D, Putnam SM: The relationship of physician medical interview style to patient satisfaction. J Fam Pract 1991;32:175-181.

30 Roter DL, Stewart M, Putnam SM, Lipkin M Jr, Stiles W, Inui TS: Communication patterns of primary care physicians. JAMA 1997;277:350-356.

31 Hemmerdinger JM, Stoddart SD, Lilford RJ: A systematic review of tests of empathy in medicine. BMC Med Educ 2007;7:24.

\$2 Christison GW, Haviland MG, Riggs ML: The medical condition regard scale: measuring reactions to diagnoses. Acad Med 2002;77:257-262.

33 Hojat M, Gonnella JS, Nasca TJ, Mangione S, Veloksi JJ, Magee M: The Jefferson Scale of Physician Empathy: further psychometric data and differences by gender and specialty at item level. Acad Med 2002;77(suppl 10):S58-60.

34 Layton JM: The use of modeling to teach empathy to nursing students. Res Nurs Health 1979;2:163176.

35 La Monica EL: Construct validity of an empathy instrument. Res Nurs Health 1981;4:389-400.

36 Davis MH: Measuring individual differences in empathy: evidence for multidimensional approach. J Pers Soc Psychol 1983;44:113-126.

37 Mehrabian A, Epstein N: A measure of emotional empathy. J Pers 1972;40:525-543.
38 Mercer SW, Maxwell M, Heaney D, Watt GC: The consultation and relational empathy (CARE) measure: development and preliminary validation and reliability of an empathy-based consultation process measure. Fam Pract 2004;21:699-705.

39 Mercer SW, McConnachie A, Maxwell M, Heaney D, Watt, GC: Relevance and practical use of the Consultation and Relational Empathy (CARE) Measure in general practice. Fam Pract 2005;22: 328-334.

40 Krupat E, Frankel R, Stein T, Irish J: The Four Habits Coding Scheme: validation of an instrument to assess clinicians' communication behavior. $\mathrm{Pa}$ tient Educ Couns 2006;62:38-45.

41 Barrett-Lennard GT: Dimensions of therapist response as causal factors in therapeutic change. Psychol Monogr 1962;76:1-36.

42 Persons JB, Burns DD: The process of cognitive therapy: the first dysfunctional thought changes less than the last one. Behav Res Ther 1986;24:619-624.

43 Rogers CR: The necessary and sufficient conditions of therapeutic personality change. J Consult Psychol 1957;21:95-103.

44 Truax C, Carkhuff R: Towards Effective Counselling and Psychotherapy: Training and Practice. Chicago, Aldline, 1967.

45 Elliott R, Filipovich H, Harrigan L, Gaynor J, Reimschuessel C, Zapadka J: Measuring response empathy: the development of a multi-component rating scale. J Couns Psychol 1982;29:379-387.

46 Watson JC, Prosser M: Development of an observer rated measure of therapist empathy; in Watson $\mathrm{JC}$, Goldman RN, Warner MS (eds): Client-Centered and Experiential Psychotherapy in the 21st Century: Advances in Theory, Research and Practice. Herefordshire, PCCS Books, 2002, pp 303-314.

47 Neumann M, Edelhauser F, Tauschel D, Fischer MR, Wirtz M, Woopen C, Haramati A, Scheffer C: Empathy decline and its reasons: a systematic review of studies with medical students and residents. Acad Med 2011;86:996-1009.

48 Myers S: Empathic listening: reports on the experience of being heard. J Hum Psychol 2000;40:148173

49 Watson JC: Re-visioning empathy; in Cain DJ, Seeman J (eds): Humanistic Psychotherapies: Handbook of Research and Practice. Washington, DC, American Psychological Association, 2001, pp 445-471.
50 Watson JC, Greenberg LS: Empathic resonance: a neuroscience perspective; in Decety J, Ickes W (eds): The Social Neuroscience of Empathy. Cambridge, MA, MIT Press, 2009, pp 125-138.

51 Hojat M, Gonnella JS, Nasca TJ, Mangione S, Vergare M, Magee M: Physician empathy: definition, components, measurement, and relationship to gender and specialty. Am J Psychiatry 2002;159: 1563-1569.

52 Mercer SW, Fitzpatrick B, Gourlay G, Vojt G, McConnachie A, Watt GC: More time for complex consultations in a high-deprivation practice is associated with increased patient enablement. Br J Gen Pract 2007;57:960-966.

53 Hojat M, Gonnella JS, Mangione S, Nasca TJ, Magee, M: Physician empathy in medical education and practice: experience with the Jefferson scale of physician empathy. Seminars Integr Med 2003;1: 25-41.

54 Kiesler D, Klein M, Mathieu P, Schoeninger D Constructive personlity change for therapy and control patients; in Rogers CR (ed): The Therapeutic Relationship and Its Impact. Madison, WI, University of Wisconsin Press, 1967, pp 251-277.

55 West CP, Shanafelt TD: The influence of personal and environmental factors on professionalism in medical education. BMC Med Educ 2007;7:29.

56 Chen JT, LaLopa J, Dang DK: Impact of Patient Empathy Modeling on pharmacy students caring for the underserved. Am J Pharm Educ 2008;72:40.

57 Henry-Tillman R, Deloney LA, Savidge M, Graham CJ, Klimberg VS: The medical student as patient navigator as an approach to teaching empathy. Am J Surg 2002;183:659-662.

58 Davis MA: A perspective on cultivating clinical empathy. Complement Ther Clin Pract 2009:15:7679.

59 Krasner MS, Epstein RM, Beckman H, Suchman AL, Chapman B, Mooney CJ, Quill TE: Association of an educational program in mindful communication with burnout, empathy, and attitudes among primary care physicians. JAMA 2009;302: 1284-1293.

60 The Compassionate Mind Foundation. www.compassionatemind.co.uk/index.html.

61 Macnaughton J: The dangerous practice of empathy. Lancet 2009;373:1940-1941. 